\title{
A New Acridone Alkaloid from Micromelum integerrimum
}

\author{
Xiao-Long Y $\mathrm{ANG},{ }^{a, c}$ Zheng-Hong XIE, ${ }^{b}$ Xian-Jun JIAng, ${ }^{b}$ Yan-Bing HuAng, ${ }^{b}$ and Ji-Kai Liu*,a \\ ${ }^{a}$ State Key Laboratory of Phytochemistry and Plant Resources in West China, Kunming Institute of Botany, Chinese \\ Academy of Sciences; Kunming 650204, P. R. China: ${ }^{b}$ BioBioPha Co., Ltd.; Kunming 650204, P. R. China: and ${ }^{c}$ Graduate \\ School of Chinese Academy of Sciences; Beijing 100049, P. R. China. \\ Received December 23, 2008; accepted April 13, 2009; published online April 14, 2009
}

A new acridone alkaloid, 1,3-dihydroxy-4-methoxy-10-methylacridone (1), was isolated from leaves of the plant Micromelum integerrimum, together with two known carbazole alkaloids, glycozolinol (2) and methyl carbazole-3-carboxylate (3). Their structures were elucidated by extensive spectroscopic analysis.

Key words Micromelum integerrimum; acridone; carbazole; glycozolinol

Micromelum integerrimum (BUCHANAN-HAMILTON ex CANDOLle) Wight \& ARnotT ex M. Roemer, of the family Rutaceae, widely distributed in China. ${ }^{1,2)}$ The plants in this genus are traditionally used to treat fever, giddiness, antimutagenic, antitumor, etc. ${ }^{2-5)}$ Previous chemical investigations on the plants of genus Micromelum have led to the isolation of prenylated coumarins, ${ }^{1,2,4-10)}$ acridone alkaloids which are characteristic constituents of the Rutaceae, ${ }^{1,4,10)}$ flavonoids, ${ }^{111)}$ dihydrocinnamic acid derivatives, ${ }^{6,8)}$ etc. To search for potentially bioactive secondary metabolites from plants of the genus Micromelum to appraise the ethnomedical properties, the present investigation was undertaken for the chemical constituents of the leaves of $M$. integerrimum collected from south part of Yunnan Province in China. It led to the isolation of one new acridone alkaloid, 1,3-dihydroxy-4methoxy-10-methylacridone (1), together with two known carbazole alkaloids, glycozolinol (2) ${ }^{11)}$ and methyl carbazole3 -carboxylate (3). ${ }^{12}$ This report deals with the isolation and structure elucidation of a new acridone alkaloid (1).

\section{Results and Discussion}

Compound 1 was obtained as white powders. Its molecular formula was determined to be $\mathrm{C}_{15} \mathrm{H}_{13} \mathrm{NO}_{4}$ on the basis of positive HR-time of flight (TOF)-MS $\left([\mathrm{M}+\mathrm{H}]^{+}\right.$at $\mathrm{m} / \mathrm{z}$ 272.0922, Calcd for $\mathrm{C}_{15} \mathrm{H}_{14} \mathrm{NO}_{4}$ 272.0923) with 10 degrees of unsaturation. The IR spectrum of $\mathbf{1}$ exhibited carbonyl and hydroxyl group absorptions at 1624 and $3234 \mathrm{~cm}^{-1}$, respectively. Its ${ }^{13} \mathrm{C}-\mathrm{NMR}$ distortionless enhancement by polarization transfer (DEPT) spectrum showed fifteen resolved peaks corresponding to fifteen carbon atoms, including signals for seven aromatic quaternary, five aromatic methine, one carbonyl, and two methyl carbons. Its ${ }^{1} \mathrm{H}-\mathrm{NMR}$ spectrum indicated the presence of five protons at $\delta 8.29(1 \mathrm{H}, \mathrm{dd}, J=8.0$, $1.5 \mathrm{~Hz}), 7.80(1 \mathrm{H}, \mathrm{m}), 7.69(1 \mathrm{H}, \mathrm{dd}, J=8.5,1.5 \mathrm{~Hz}), 7.31$ $(1 \mathrm{H}, \mathrm{m}), 6.22(1 \mathrm{H}, \mathrm{s})$, two methyl protons at $\delta 4.10(3 \mathrm{H}, \mathrm{s})$, $3.70(3 \mathrm{H}, \mathrm{s})$, one dissociated $-\mathrm{OH}$ at $\delta 9.21(1 \mathrm{H}, \mathrm{brs})$ and one chelated $-\mathrm{OH}$ at $\delta 14.58(1 \mathrm{H}, \mathrm{s})$.

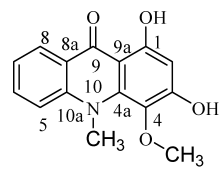

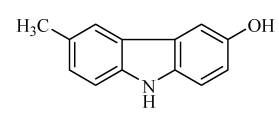

2

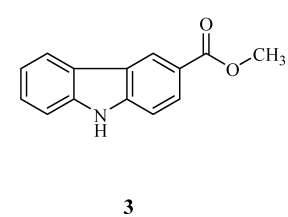

The analysis of the ${ }^{1} \mathrm{H}$ - and ${ }^{13} \mathrm{C}-\mathrm{NMR}$ spectral data of $\mathbf{1}$ indicated the structure of $\mathbf{1}$ is very similar to the known compound, 1-hydoxy-3,4-dimethoxy-10-methyl-9-acridanone, reported in the literature ${ }^{13)}$ except for the absence of one methoxy group. It suggested that 1 possesses the same skeleton and substitution pattern. The distinct difference between them is the C-3 hydroxyl group at $\delta 9.21$ (br s, $3-\mathrm{OH})$ of $\mathbf{1}$ is instead of the C-3 methoxy group at $\delta 3.94\left(\mathrm{~s}, 3-\mathrm{OCH}_{3}\right)$ in the known compound. The heteronuclear multiple bond connectivity (HMBC) data of $\mathbf{1}$ demonstrated the following key correlations: $\mathrm{H}-2$ to $\mathrm{C}-1, \mathrm{C}-3, \mathrm{C}-4, \mathrm{C}-9 \mathrm{a} ; \mathrm{N}^{-} \mathrm{CH}_{3}$ to $\mathrm{C}-4 \mathrm{a}, \mathrm{C}-$ 5 ; $\mathrm{H}-8$ to $\mathrm{C}-9$, which were in consistency with the structure. In the light of the evidence mentioned above, the structure of 1 was finally established as 1,3-dihydroxy-4-methoxy-10methyl-acridone (Fig. 1).

The structures of two known compounds were identified as glycozolinol (2), ${ }^{11)}$ and methyl carbazole-3-carboxylate (3), ${ }^{12)}$ respectively, by comparision of their spectroscopic data with literature values.

\section{Experimental}

General Experiment Procedures IR spectra were obtained with a Tensor 27 with $\mathrm{KBr}$ pellets. NMR spectra were recorded on Bruker AV-400 and Bruker DRX-500 spectrometers with tetramethylsilane (TMS) as an internal standard. MS spectra were recorded with a VG Autospec-3000 spectrometer. HR-TOF-MS were recorded with an API QSTAR Pulsar 1 spectrometer. UV spectra were recorded on a Shimadzu UV-2401PC spectrophotometer. Silica gel (200-300 mesh, Qingdao Marine Chemical Inc., P. R. China) and Sephadex LH-20 (Amersham Biosciences, Sweden) were used for column chromatography.

Plant Material The leaves of Micromelum integerrimum were collected from Yunnan Province, China, and identified by Prof. Hua Peng. The voucher specimen was deposited in the Herbarium of Kunming Institute of Botany, Chinese Academy of Sciences.

Extraction and Isolation The air-dried powdered leaves $(12 \mathrm{~kg})$ of $M$. integerrimum were extracted three times with $95 \% \mathrm{EtOH}(41 \times 3)$. After removal of the solvent in vacuo, the residues $(350 \mathrm{~g})$ were subjected to silica gel column chromatography (CC), eluted with petroleum ether/acetone $(98: 2,95: 5,90: 10,80: 20,50: 50, \mathrm{v} / \mathrm{v})$ to afford six fractions $(\mathrm{A}-\mathrm{E})$. The fraction $\mathrm{D}(2.0 \mathrm{~g})$ eluted with petroleum ether/acetone $(95: 5)$ was further purified by repeated silica gel $\left(\mathrm{CHCl}_{3} /\right.$ acetone) and Sephadex $\mathrm{LH}-20 \mathrm{CC}$

Fig. 1. Structures of Compounds $\mathbf{1}-\mathbf{3}$

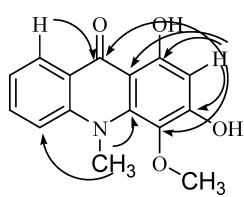

Fig. 2. Key HMBC Correlations of $\mathbf{1}$ 
Table 1. NMR Spectral Data (Acetone- $d_{6}$ ) for $\mathbf{1}$

\begin{tabular}{lrlllr}
\hline \hline No. & \multicolumn{1}{c}{$\delta_{\mathrm{C}}$} & \multicolumn{1}{c}{$\delta_{\mathrm{H}}$} & \multicolumn{1}{c}{ No. } & \multicolumn{1}{c}{$\delta_{\mathrm{C}}$} & \multicolumn{1}{c}{$\delta_{\mathrm{H}}$} \\
\hline 1 & $159.3(\mathrm{~s})$ & & $8 \mathrm{a}$ & $122.0(\mathrm{~s})$ & \\
2 & $97.5(\mathrm{~d})$ & $6.22(\mathrm{~s})$ & 9 & $181.9(\mathrm{~s})$ & \\
3 & $128.5(\mathrm{~s})$ & & $9 \mathrm{a}$ & $106.4(\mathrm{~s})$ & \\
4 & $161.9(\mathrm{~s})$ & & $10 \mathrm{a}$ & $145.8(\mathrm{~s})$ & \\
$4 \mathrm{a}$ & $139.5(\mathrm{~s})$ & & $\mathrm{N}-\mathrm{CH}_{3}$ & $40.1(\mathrm{q})$ & $4.10(\mathrm{~s})$ \\
5 & $117.0(\mathrm{~d})$ & $7.69(\mathrm{dd}, 8.5,1.5)$ & $\mathrm{O}-\mathrm{CH}_{3}$ & $61.8(\mathrm{q})$ & $3.70(\mathrm{~s})$ \\
6 & $134.9(\mathrm{~d})$ & $7.80(\mathrm{~m})$ & $1-\mathrm{OH}$ & & $14.58(\mathrm{~s})$ \\
7 & $122.3(\mathrm{~d})$ & $7.31(\mathrm{~m})$ & $3-\mathrm{OH}$ & & $9.21(\mathrm{~s})$ \\
8 & $126.4(\mathrm{~d})$ & $8.29(\mathrm{dd}, 8.0,1.5)$ & & & \\
& & & & & \\
\hline
\end{tabular}

$\left(\mathrm{CHCl}_{3} / \mathrm{MeOH}, 1: 1\right)$ to afford $2(70 \mathrm{mg})$ and $3(26 \mathrm{mg}) . \mathbf{1}(61 \mathrm{mg})$ was obtained from fraction $\mathrm{E}$ after repeated silica gel $\left(\mathrm{CHCl}_{3} /\right.$ acetone) and Sephadex LH-20 CC $\left(\mathrm{CHCl}_{3} / \mathrm{MeOH}, 1: 1\right)$.

1,3-Dihydroxy-4-methoxy-10-methylacridone (1): White powder. UV $\lambda_{\max }(\mathrm{MeOH}): 280,337 \mathrm{~nm}$. IR (KBr): 3234, 1624, 1580, 1410, $1158 \mathrm{~cm}^{-1}$. ${ }^{1} \mathrm{H}$ - and ${ }^{13} \mathrm{C}-\mathrm{NMR}$ spectral data: see Table 1. EI-MS (70 eV) $\mathrm{m} / \mathrm{z}$ (\%): 271 (32) $[\mathrm{M}]^{+}, 256$ (77) $[\mathrm{M}-\mathrm{Me}]^{+}, 228$ (100), 149 (20). Positive HR-TOF-MS $m / z: 272.0923[\mathrm{M}+\mathrm{H}]^{+}\left(\right.$Calcd for $\left.\mathrm{C}_{15} \mathrm{H}_{14} \mathrm{NO}_{4}, 272.0922\right)$.

Acknowledgments This work was financially supported by National Basic Research Program of China (973 Program, 2009CB522300) and the R\&D funds from BioBioPha Co., Ltd.

\section{References}

1) Sohrab M. H., Chowdhury R., Hasan C. M., Rashid M. A., Biochem. Syst. Ecol., 32, 829-831 (2004).

2) Rahmani M., Susidarti R. A., Ismail Hazar B. M., Sukari M. A., Hin Taufiq-Yap Y., Lian G. E. C., Ali A. M., Kulip J., Waterman P. G., Phytochemistry, 64, 873-877 (2003).

3) Nakahara K., Trakoonttvakorn G., Alzoreky N. S., Ono H., OnishiKamey M., Yoshidam M., J. Agric. Food Chem., 50, 4796- 4802 (2002).

4) Cassady J. M., Ojima O., Chang C., Mclaughli J. L., J. Nat. Prod., 42, 274-278 (1979).

5) Tantishaiyakul V., Pummangura S., Chaichantipwth C., J. Nat. Prod., 49, 180-181 (1986).

6) Kamperdick C., Phuong N. M., Sung T. V., Schmidt J., Adam G., Phytochemistry, 52, 1671-1676 (1999).

7) Sohrab M. H., Hasan Choudhury M., Rashid M. A., Biochem. Syst. Ecol., 27, 535-537 (1999).

8) Rahmani M., Taufiq-Yap Y. H., Ismail H. B. M., Sukari A., Waterman P. G., Phytochemistry, 37, 561—564 (1994).

9) Das S., Baruah Robindra H., Sharma R. P., Barua Jogendra N., Kulanthaivel P., Herz W., Phytochemistry, 23, 561-564 (1984).

10) Bowen I. H., Christopher P. K. P. W., Phytochemistry, 21, 433-437 (1982).

11) Bhattacharyya P., Sarkar T., Chakraborty A., Indian J. Chem., 23B, 49-51 (1984).

12) Li W. S., Mcchesney J. D., El-Feraly F. S., Phytochemistry, 30, $343-$ 346 (1991).

13) Baudouin G., Tillequin F., Michel K., Dau Marie-Elise T. H., Guilhem J., Pusset J., Chauviere G., J. Nat. Prod., 48, 260-265 (1985). 